\title{
Mortality and causes of death in Crohn's disease. Review of 50 years' experience in Leiden University Hospital
}

\author{
Irene T Weterman, I Biemond, A S Peña
}

\begin{abstract}
Six hundred and seventy one patients $(52.5 \%$ women) with Crohn's disease seen at Leiden University Hospital between 1934 and 1984 were identified. Follow up was $98.2 \%$ complete. Sixty four $(9.7 \%)$ of the 659 patients died. The cause of death was related to Crohn's disease in 34 patients, probably related to the disease in four, and unrelated, from incidental causes, in 25 . The cause of death could not be identified in one patient. There was a significant decrease of deaths related to the disease after 1973. Causes of death such as amyloidosis and malnutrition have disappeared and postoperative deaths have decreased. The standardised mortality ratio showed an excess mortality of 2.23 for all patients. It was higher for women (3.30) than for men (1.76). A comparison of two recent 10 year periods showed a significant decrease in standardised mortality ratio in men but not in women. Patients whose disease started before the age of 20 years had an excess mortality compared with older patients. This study supports the view that the prognosis of Crohn's disease has improved in general but high quality medical and surgical management is important particularly for younger patients.
\end{abstract}

Mortality studies among patients with Crohn's disease have been examined in patients referred to special centres such as the one reported on here and in a defined epidemiological setting. ${ }^{1-5}$ Most studies have shown an excess risk among patients with Crohn's disease. In referral centres the standardised mortality ratios ranged from 2 to $5 \cdot 6$, while in population based studies they ranged from 1.3 to $2 \cdot 2$ (reviewed by Mayberry and Rhodes $^{6}$ ). Few clinical analyses of mortality have been reported. ${ }^{78}$

In the recent study from Birmingham, England, it was suggested that, apart from cancer of the digestive tract, with appropriate medical and surgical treatment of patients with Crohn's disease the excess mortality previously associated with this disease should be eliminated. ${ }^{8}$ In fact the population based study from Copenhagen ${ }^{7}$ showed that survival in the first 10 years after the diagnosis of Crohn's disease did not differ from that of the age and sex-matched background population.

The aim of the present study was to evaluate, analyse, and compare the mortality and causes of death observed over 50 years from 1934 to 1984 in Leiden University Hospital. We compare the observed mortality and causes of death described in a previous retrospective study ${ }^{10}$ and the 10 year period 1964-73 with a prospective 10 year period thereafter.

\section{Methods}

PATIENTS

A total of 671 patients ( $52.5 \%$ women) with Crohn's disease seen at the Leiden University Hospital from 1934 to 1984 were included in the study. These patients came from the Leiden region as well as from other parts of The Netherlands (more than 60\%) since this department is a referral centre for patients with inflammatory bowel disease. The study includes inpatients and outpatients. Before presentation in Leiden two thirds of the patients had been admitted at least once to another hospital and $30 \%$ had been admitted three or more times elsewhere. The Figure shows the number of patients according to sex in five year periods of presentation to Leiden. In $31 \cdot 7 \%$ the onset of Crohn's disease occurred below the age of 20 years and in over $70 \%$ of the patients the disease started before age 30 .

\section{CLINICAL FOLLOW UP}

Patients were seen regularly at the outpatient clinic. At the time of the review, however, 130 patients were no longer attending the depart-

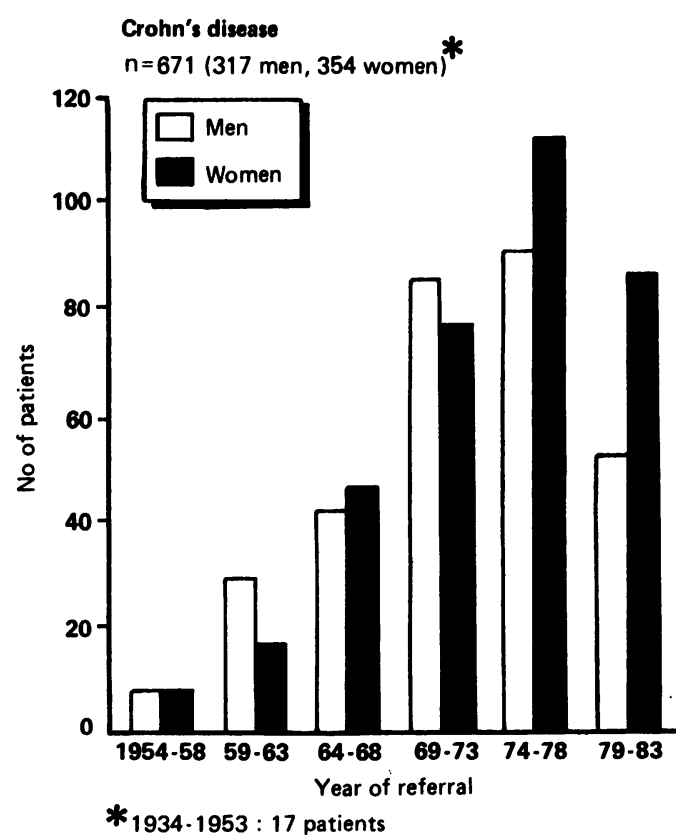

Numbers of men and women presenting to Leiden University Hospital with Crohn's disease between 1954 and 1983 in five year periods.
Gastroenterology, University Hospita The Netherlands rene T Weterman Biemond 
ment. Information on their outcome was obtained from their general practitioners, internists, or the City Council Register. In case of death the cause was verified from these sources and from the National Deaths Register. Copies of the death certificates were obtained when available. For only $12(1 \cdot 8 \%)$ of the 671 patients no information could be obtained. Seven were known to have emigrated. These 12 patients were followed up from the time of presentation to emigration from Holland or termination of regular review, but were excluded from the calculations concerning mortality thereafter.

\section{STATISTICAL METHODS}

The probability of dying per year from diagnosis was computed from the number of deaths and the patient-years at risk in each interval yearly up to five years and afterwards in five year periods.

The standardised mortality ratio or relative risk of dying was calculated by dividing the observed number of deaths by the expected number of deaths calculated from the age and sex-specific death rates for the whole Dutch population in 1984 as published by the Central Bureau of Statistics in 1974

The cumulative relative risk was calculated from the standardised mortality ratio - that is, observed mortality divided by the expected mortality at each point in time.

\section{Results}

\section{DURATION OF DISEASE AT PRESENTATION} IN LEIDEN

The percentage of patients who presented with disease of less than one year's duration was $9.5 \%$, one to five years' duration $49 \%$, six to 10 years $20.5 \%$, and over 10 years $21 \%$.

\section{SITE OF DISEASE AT PRESENTATION IN LEIDEN}

The small intestine was affected in $30.7 \%$ of patients; $32.6 \%$ had disease of the small intestine and colon or rectum, or both; $35.9 \%$ had disease of the colon or rectum, or both; and in only $0.8 \%$ were other sites affected.

\section{CAUSE OF DEATH}

During a mean follow up of $\mathbf{9 . 9}$ years (range 0.5-49 years) after presentation at Leiden the overall crude mortality was $9 \cdot 7 \%$ since 64 of 659 patients died. Causes of death were divided into related, probably related, and unrelated causes (Table I). The results are divided in two periods. Patients who died before January 1974 have been described ${ }^{10}$ and are compared with those who died in the subsequent 10 year period of follow up and with those who died in the 10 year period 1964 to 1973 .

\section{RELATED DEATHS}

There were 34 related deaths, 20 of them in the immediate postoperative period. As Table I shows there was a significantly greater decreased mortality related to the disease in the second
TABLE I Cause of death in patients with Crohn's disease in two different periods (Number of postoperative deaths in parentheses)

\begin{tabular}{lccccc}
\hline & \multicolumn{2}{l}{ Deaths } \\
\cline { 2 - 3 } \cline { 5 - 6 } Cause & \multicolumn{2}{l}{ Before 1974 } & & \multicolumn{2}{l}{ After 1 fan 1974 } \\
\cline { 2 - 3 } \cline { 5 - 6 } & No & $\%$ & & No & $\%$ \\
\hline Related to disease & $19(11)$ & $79 \cdot 2^{\star}$ & & $15(9)$ & $37 \cdot 5^{\star}$ \\
Probably due to disease & 2 & $8 \cdot 3$ & 2 & $5 \cdot 0$ \\
Unrelated to disease & 3 & $12 \cdot 5^{\star}$ & 22 & $55 \cdot 0^{\star}$ \\
Unknown & - & & 1 & $2 \cdot 5$ \\
Total No of deaths & 24 & $100 \cdot 0$ & & 40 & $100 \cdot 0$ \\
Total No of patients & 316 & & 343 & \\
\hline
\end{tabular}

$\star$ Difference significant $(\mathrm{p}<0.01)$.

period than in the period before 1974. Furthermore, fewer patients died after surgery in the second period.

Four patients died from amyloidosis, three from malnutrition. Two patients died of colorectal cancer and two died due to an electrolyte disturbance. Massive bleeding from the large intestine was the cause of death in two patients. Finally, a man with extensive disease of the small intestine died at the age of 61 due to hypomagnesaemia in 1970 .

\section{PROBABLY RELATED}

Four patients died of causes which may be considered to be related to Crohn's disease. One cachectic woman died elsewhere from pyelonephritis, one severely incapacitated man died suddenly at home due to a saddle embolus on the bifurcation, one man died with pancarditis during a phase of inactive Crohn's disease, and one woman with primary sclerosing cholangitis died due to liver insufficiency.

\section{UNRELATED DEATHS}

There were 25 unrelated deaths (Table I). The causes of death were malignancy outside the gastrointestinal tract in eight patients: one ovarian carcinoma and one carcinoma of the cervix, one retroperitoneal reticulosarcoma, one sarcoma of the knee, two bronchial carcinomas, one carcinoma of the ampulla of Vater, and one Hodgkin's disease. Five patients died in accidents, four patients had cerebrovascular disease, four had ischaemic heart disease, two had pulmonary disease, one patient died due to amyotrophic lateral sclerosis, and one patient with psychiatric disease diagnosed before the onset of Crohn's disease committed suicide.

One man died abroad at the age of 53 . No information was available about the cause of death.

The expected number of deaths calculated from the general population was nearly equal to the number of deaths unrelated to Crohn's disease (29 deaths expected and 25 observed; 95\% confidence interval: 17 to 37 ).

\section{MEAN AGE AT DEATH}

Mean (SD) age at death in patients with Crohn's disease who died of causes related to the disease was $45 \cdot 1(15 \cdot 2)$ and $37 \cdot 5(13 \cdot 9)$ years for men and women respectively. The mean age at death for 
TABLE II Standardised mortality ratio (SMR) in a series of 658 patients with Crohn's disease (1934-84)

\begin{tabular}{|c|c|c|c|c|c|}
\hline & $\begin{array}{l}\text { Observed } \\
\text { deaths }\end{array}$ & $\begin{array}{l}\text { Expected } \\
\text { deaths }\end{array}$ & $S M R^{\star}$ & $\begin{array}{l}95 \% \\
\text { Confidence } \\
\text { interval }\end{array}$ & $p$ value \\
\hline $\begin{array}{l}\text { All patients } \\
\text { Men }(n=307) \\
\text { Women }(n=351)\end{array}$ & $\begin{array}{l}64 \\
35 \\
29\end{array}$ & $\begin{array}{r}28 \cdot 7 \\
19 \cdot 9 \\
8 \cdot 8\end{array}$ & $\begin{array}{l}2 \cdot 23 \\
1 \cdot 76 \\
3 \cdot 30\end{array}$ & $\begin{array}{l}1.75 \text { to } 2.85 \\
1.26 \text { to } 2.45 \\
2.29 \text { to } 4.73\end{array}$ & $\begin{array}{l}<0.001 \\
<0.001 \\
<0.001\end{array}$ \\
\hline
\end{tabular}

«Standardised to the mortality of the general population in 1974

tp value corresponding to $\chi^{2}$.

TABLE III Mortality from all causes in patients with Crohn's disease after diagnosis

\begin{tabular}{llcllll}
\hline $\begin{array}{l}\text { Duration of disease } \\
\text { after diagnosis } \\
\text { (years) }\end{array}$ & $\begin{array}{l}\text { No of } \\
\text { patients } \\
\text { at risk }\end{array}$ & $\begin{array}{l}\text { No of } \\
\text { deaths }\end{array}$ & $\begin{array}{l}\text { Lost to } \\
\text { follow up } \\
\text { during } \\
\text { interval }\end{array}$ & $\begin{array}{l}\text { Expected } \\
\text { No } \\
\text { of deaths }\end{array}$ & $R R^{\star}$ & p value \\
\hline 0 & 671 & 6 & 6 & $1 \cdot 38$ & $4 \cdot 35$ & $<0 \cdot 001$ \\
$1-2$ & 659 & 3 & 33 & $2 \cdot 77$ & 1.08 & $=0 \cdot 30$ \\
$3-4$ & 623 & 3 & 41 & 2.47 & 1.21 & $=0 \cdot 24$ \\
$5-9$ & 579 & 17 & 157 & 7.06 & 2.41 & $<0.0001$ \\
$10-15$ & 405 & 10 & 136 & 6.07 & 1.65 & $=0 \cdot 11$ \\
$15-19$ & 259 & 11 & 108 & 5.32 & 2.07 & $=0.012$ \\
$>20$ & 140 & 14 & - & 5.62 & $2 \cdot 49$ & $=0.00005$ \\
\hline
\end{tabular}

*Cumulative relative risk: observed/expected ratio.

TABLE IV Standardised mortality ratio (SMR) in patients with Crohn's disease

\begin{tabular}{lllllll}
\hline Period of study & $\begin{array}{l}\text { Patients } \\
(n)\end{array}$ & $\begin{array}{l}\text { Observed } \\
\text { deaths }\end{array}$ & $\begin{array}{l}\text { Expected } \\
\text { deaths }\end{array}$ & SMR & $\begin{array}{l}\text { 95\% } \\
\text { Confidence } \\
\text { interval }\end{array}$ & p value \\
\hline $1964-73$ & 250 & 8 & 3.0 & $2.67 \dagger$ & 1.35 to 5.26 & $<0.01$ \\
& M 127 & 5 & 2.1 & 2.38 & 1.02 to 5.57 & $<0.05$ \\
$1974-83$ & F 123 & 3 & 0.9 & 3.33 & 1.13 to 9.80 & $<0.05$ \\
& M & 14 & 7.1 & $1.97 \dagger$ & 1.17 to 3.31 & $<0.01$ \\
& M 146 & 6 & 5.3 & 1.13 & 0.52 to 2.47 & NS \\
& F 197 & 8 & 1.8 & 4.44 & 2.25 to 3.56 & $<0.001$ \\
\hline
\end{tabular}

^Standardised to the mortality of the general population in 1974.

†Difference not significant.

NS=not significant. risk of dying is highest in the first year after diagnosis and falls subsequently, but increases in the period between five and nine years after diagnosis, as well as after 20 years.

CUMULATIVE RELATIVE RISKS OF DYING DURING THE TWO MOST RECENT IO YEAR PERIODS

Table IV shows that the cumulative relative risk of dying decreased in the last 10 year period, although the difference is not significant. The risk of dying was higher in women than in men in both periods.

\section{Discussion}

Although this study suffers from the difficulties of coming from a referral centre and not from an unselected and defined population, the results suggest and support the figures from Hellerss and the recent study from Birmingham ${ }^{8}$ that the prognosis concerning mortality has improved. This study also shows that the excess mortality was due to Crohn's disease since the number of unrelated deaths did not differ from that in the general population. It has been suggested that in England over time the proportion of patients referred with severe problems has increased and most of the patients are cared for in general hospitals. The health system in The Netherlands is different from the one in the United Kingdom and it is our experience that in the past decade patients are being referred earlier to specialised centres with milder disease in general. Therefore, not only the improvements in medical and surgical management may be responsible for the gain in survival but also the change in referral pattern.

Interestingly, when the causes of death are analysed, amyloidosis has disappeared and not a single case with this complication was seen in this centre after 1975.

Only four patients have developed malignancy of the colon or rectum involved with Crohn's disease. Two of them died as a consequence of the malignancy during the study, one a year later and the other is still alive 10 years after resection of a Dukes's stage A colon carcinoma. These malignancies developed $10,17,21$, and 27 years after onset of the disease. The group in Birmingham $^{8}$ found that in their series cancer of the digestive tract was now the most common cause of related death in Crohn's disease. Twenty two patients died from cancer of the digestive tract out of 92 patients who died of related deaths. Binder $e t a l$ reported one death due to malignancy in 185 patients after 10 years of follow up. The cancer was localised in the ileum. We have not observed any patient with Crohn's disease developing malignancy of the small intestine.

As in other series ${ }^{34}$ the risk of dying was significantly higher in patients whose disease started before the age of 20 .

In the present series the risk of dying was influenced by sex. Women had an excess mortality compared to men, as was the case in the series from Oxford ${ }^{1}$ but not from Birmingham. ${ }^{4}$

From the reported studies and from the present series, despite differences of patient identification and referral patterns, it seems that
OVERALL CUMULATIVE RELATIVE RISK OF DYING The cumulative relative risk of dying, which is the ratio of the observed to the expected mortality, is given in Table III. The overall relative 
the excess mortality has decreased but is still higher than expected for the general population, especially in referral units where the standardised mortality ratio is twice normal. Therefore, vigilance and appropriate medical and surgical management are mandatory.

We thank Agnes $M$ van Gent, MD, for data collection.

1 Truelove SC, Peña AS. Course and prognosis of Crohn's disease. Gut 1976; 17: 192-201.

2 Prior P, Fielding JF, W aterhouse JA, Cooke WT. Mortality in Prior P, Fielding JF, Waterhouse JA, Coo
Crohn's disease. Lancet 1970; i: 1135-7.

3 Mayberry JF, Newcombe RG, Rhodes J. Mortality in Crohn's disease. Qf Med 1980; 49: 63-8.
4 Prior P, Gyde S, Cooke WT, Waterhouse JAH, Allan RN. Mortality in Crohn's disease. Gastroenterology 1981; 80: Mortality in Crohn's disease. Gastroenterology 1981; 80:

5 Hellers G. Crohn's disease in Stockholm County 1955-1974. A study of epidemiology, results of surgical treatment and long-term prognosis. Acta Chir Scand 1979; 490 suppl.

6 Mayberry JF, Rhodes J. Epidemiological aspects of Crohn's disease: a review of the literature. Gut 1984; 25: 886-99.

7 Binder V, Hendriksen C, Kreiner S. Prognosis in Crohn's disease- based on results from a regional patient group from the county of Copenhagen. Gut 1985; 26: 146-50.

8 Andrews HA, Lewis P, Allan RN. Mortality in Crohn's disease - a clinical analysis. Qf Med 1989; 71: 399-405.

9 Weterman IT. Course and long-term prognosis of Crohn's disease. MD thesis. Leiden: Leiden University, 1976.

10 Weterman IT. Retrospective study of 226 patients with Crohn's disease. In: Weterman IT, Peña AS, Booth CC, eds. The management of Crohn's disease. Amsterdam: Excerpta Medica, 1976: 135-7. 